\section{Inappropriate use of emergency services: a systematic review of prevalence and associated factors}

\author{
Prevalência e fatores associados ao uso \\ inadequado do serviço de emergência: \\ uma revisão sistemática da literatura
}

Maria Laura Vidal Carret 1,2

Anaclaudia Gastal Fassa 1

Marlos Rodrigues Domingues 1,3

\footnotetext{
${ }^{1}$ Faculdade de Medicina, Universidade Federal de Pelotas, Pelotas, Brasil.

2 Faculdade de Saúde, Universidade Católica de Pelotas, Pelotas, Brasil.

3 Programa de Pós-graduação em Saúde Coletiva

Universidade do Vale do Rio dos Sinos,

São Leopoldo, Brasil.

Correspondence M. L. V. Carret

Programa de Pós-graduação em Epidemiologia, Faculdade de Medicina, Universidade Federal de Pelotas. Av. Duque de Caxias 250, 3o piso, Pelotas, $R S$ 96030-002, Brasil. mvcarret@hotmail.com
}

\begin{abstract}
This systematic review aimed to measure the prevalence of inappropriate emergency department (ED) use by adults and associated factors. The review included 31 articles published in the last 12 years. Prevalence of inappropriate ED use varied from 20 to $40 \%$ and was associated with age and income. Female patients, those without co-morbidities, without a regular physician, without a regular source of care, and those not referred to the ED by a physician also showed more inappropriate ED use, with the relative risk varying from 1.12 to 2.42. Difficulties in accessing primary health care (difficulties in setting appointments, longer waiting periods, and short business hours at the primary health care service) were also associated with inappropriate ED use. Thus, primary care requires fully qualified patient reception and efficient triage to promptly attend cases that cannot wait. It is also necessary to orient the population on situations in which they should go to the ED and on the disadvantages of consulting the ED when the case is not really urgent.
\end{abstract}

Emergency Medical Services; Health Services Misuse; Adult; Evaluation Studies

\section{Introduction}

Emergency treatment aims to perform procedures to immediately relieve well-circumscribed situations, and is not intended to include on-going care 1 . However, patients frequently seek the emergency department (ED) to obtain immediate attention in order to perform tests and administer medication to relieve symptoms. Although this may appear appropriate from the patient's perspective (given existing limitations in other levels of health care), this type of use places a burden on the health system and increases the demand on the ED for care that could be managed better at other levels and that in a sense competes with true emergency cases. Meanwhile, such demand generates a kind of care that fails to create a bond with the health service (in which patients would receive not only treatment to relieve their immediate symptoms, but also health education) or to link with on-going care in order to prevent complications and new illnesses 2,3,4. Such use of ED services is thus considered inappropriate.

The inappropriate use of ED services is a common problem in various countries, and the issue has thus been studied for more than two decades 5 . However, the wide range of criteria used to define inappropriate use of ED services has been an obstacle to systematic reviews on the topic ${ }^{6}$. Numerous studies have evaluated its prevalence and many have also examined factors associated with such inappropriate use, but most 
studies have been limited to evaluating sociodemographic factors, without examining other aspects in depth, such as those related to other levels of care.

The existing systematic reviews approach the historical profile of inappropriate ED use in the United States 7, criteria to define inadequacy of ED services 8, patterns in ED use by the elderly 9, and the role of expanding primary health care and bad experiences in primary health care in determining inappropriate ED use, in publications from 1971 to 1997 10. However, despite the existing reviews, there are no recent articles summarizing the findings on prevalence of inappropriate ED use or its determinants, particularly those related to health needs and access to health services. Thus, the current article presents a systematic literature review, exploring the principal criteria used to define inappropriate ED use, identifying the problem's prevalence and examining the state-of-the-art on factors associated with inappropriate ED use. Knowledge of the prevalence and factors associated with inappropriate ED use can help orient public policies to reduce the problem.

\section{Methods}

A literature review was performed in the following databases: MEDLINE (International Health Sciences Literature), LILACS (Latin American and Caribbean Health Sciences Literature), SciELO (Scientific Electronic Library Online), Harvard Electronic Library, website of the World Health Organization (http://www.who.int), website of Free Medical Journals (http://www.freemedical journals.com), and the Library of the Graduate Course in Epidemiology at the Federal University in Pelotas, Brazil. In addition, all the references from the initially selected articles were reviewed. Inclusion criteria for the articles were: indexed articles, published since 1995, with samples of adults, measuring prevalence and/or factors associated with inappropriate use of emergency services. Articles were excluded that did not clearly present the criteria used to define the outcome.

The following words were searched in "all fields": inappropriate, inadequate, nonurgent, non-urgent, misuse, appropriateness, unnecessary, nonemergency, demand, visits, consultation AND emergency department, emergency service, emergency services, emergency room, urgency department, urgency service, urgency services, urgency room, and their equivalents in Spanish and Portuguese.

\section{Qualitative evaluation}

The selected articles that evaluated factors associated with inappropriate ED use were classified according to the criteria proposed by Downs \& Black 11. Since no experimental study was selected, the items that only applied to this type of study were excluded. Using this criterion, we evaluated whether:

- the study's hypotheses and objectives were described;

- the principal outcomes to be measured were described;

- the characteristics of the subjects included in the study were described (cohort or case-control);

- the distribution of the principal confounding factors in each comparison group was described;

- the study's principal findings were described;

- in cohort studies, the characteristics of the subjects lost to follow-up were described;

- the probability of association ( $p$-value) with the principal outcomes was reported precisely;

- the sample selected for the study was representative;

- the sample included in the study was representative;

- analyses not originally planned in the project were clearly indicated;

- in cohort studies, the different follow-up times were adjusted in the analysis; or, in case-control studies, the time transpired between determinants and outcome was the same for cases and controls;

- the statistical tests used to measure the principal outcomes were appropriate;

- the measurements to evaluate the principal outcomes were accurate;

- the individuals in the different groups were recruited from the same population;

- the individuals in the different groups were recruited during the same time period;

- the principal confounding factors were adequately adjusted in the analysis;

- losses of individuals during follow-up were considered; and

- the study's power to detect important effects was sufficient, with a significance level of $5 \%$.

Two epidemiologists performed the scores, with a total of 18 items assessed according to the Downs \& Black criteria, with a maximum score of 19 points. Whenever there was disagreement, the two epidemiologists conferred until reaching a consensus. 


\section{Data extraction and synthesis}

Data were extracted from the studies with the respective year of publication, country where the study was performed, and design. Evaluation of factors associated with inappropriate ED use was based on the Downs \& Black score, study characteristics, and effect measurements, analyzing the consistency of the results.

\section{Results}

A total of 5,124 articles were identified in the online databases, of which 4,938 were ruled out by reading the title and abstract, since, since they did not specify the study outcome. Of the 186 remaining studies, 31 were selected that evaluated prevalence rates and 22 that measured factors associated with inappropriate ED use.

\section{Criteria for defining inappropriate ED use}

The criteria for defining an inappropriate ED visit varied considerably between the studies, and the following were the most frequent: waiting time until receiving care, medical assessment of risk of death or target organ injury, and resources needed for care (whether only available in the ED or not). Other aspects included: self-perceived urgency, need for diagnostic tests, immediate treatment, and/or observation, and others (Table 1). Each of these items also varied greatly. For example, the list of tests considered in the definition of urgencies varied for each criterion.

We identified two standardized criteria for defining inappropriate use: (i) the Canadian Triage and Acuity Scale (CTAS) 12, which classifies ED care in five levels, based on the waiting time allowed for the patient to be examined by the physician, risk of death, vital signs, pain level, possibility of complications, and origin of the injury and (ii) the Hospital Urgencies Appropriateness Protocol (PAUH) 13,14,15,16, defining the case as urgent whenever one of the items evaluated was met. This protocol considers criteria of severity (for example, altered vital signs and active hemorrhages), diagnosis (like orders for laboratory or imaging tests), treatment (like need for IV medication), and origin of the need for seeking the ED (for example: coming directly from a traffic accident or symptoms suggesting vital urgency) (Table 1).

\section{Prevalence}

Prevalence of inappropriate ED use varied from 10 to $90 \%$, based on the criterion used, and in nearly half of the studies it varied from 24 to $40 \% 6,12,13,14,16,17,18,19,20,21,22,23,24,25,26$. All these articles presented similar criteria, evaluating the number of hours the patient could wait without risk of death, need for tests or treatments, need for hospitalization, possibility of treatment at another level of care, and observation time (Table 1).

Of the 11 articles that reported prevalence rates for inappropriate ED use greater than or equal to $45 \%$, seven $6,15,27,28,29,30,31,32$ used more rigorous criteria to define appropriate ED use, such as requiring observation for more than 12 hours or hospitalization; three other 33,34,35 used samples that excluded populations presenting greater severity. Meanwhile, among seven studies $6,36,37,38,39,40,41$ that found prevalence rates lower than $20 \%$, three used self-perceived urgency as the definition of appropriate ED use 6,37,38; two others used more rigorous criteria to define inappropriate use 36,41; and the study by Finn et al. 40 evaluated a lower-risk population for inappropriate use (65 years or older) (Table 1).

\section{Characterization of studies on association}

The review included 19 cross-sectional studies, two case-controls, and one cohort. Eight studies conducted were in European countries, seven in North America, one in Central America, one in Oceania, three in China, and two in South America.

The methodological score varied from 5 to 13 points, with a mean of 9 (median $=8)$. Of the studies evaluated, five had a score or 7 or less and eight had scores of 10 or more. In addition to the limitations related to study design (six items could not be scored in 19 studies, since they were cross-sectional), the principal limitations in the Downs \& Black classification were those related to data analysis, such as performing only univariate analysis, and the failure to describe the strategy used in the multivariate analysis, or to the sample's representativeness. Table 2 shows the scores for each study.

\section{Characteristics of inappropriate ED use}

As for time of arrival at the ED, the early morning hours (midnight to 08:00 AM) was the period with the most appropriate ED use 13,14,21,22,23,28, while the morning and afternoon shifts showed the heaviest ED use by patients with inappropriate complaints 13,21. Day of the week was not associated with inappropriate use 12,14,22,37. After controlling for confounding factors, duration of symptoms was directly associated with inappropriate ED use 12,13,22,37. 
Criteria for definition of inappropriate emergency department use, 2007.

\begin{tabular}{|c|c|c|c|c|c|}
\hline Article & Protocol & Country & $\begin{array}{c}\text { Year of } \\
\text { publication }\end{array}$ & Criterion & $\begin{array}{c}\text { Prevalence of } \\
\text { inappropriate use }\end{array}$ \\
\hline
\end{tabular}

\section{North America}

Lowe \& Bindman 6

Criterion of the San Francisco General Hospital

Derlet et al. 41

USA

1995

Gill \& Riley 38

Gill et al. 29

Rubin \& Bonnin 24

USA

1995

Petersen et al. 34

Based on study by

USA

Baker et al.

Young et al. 35

USA

$$
\text { on a total of } 7 \text { criteria: }
$$

- According to patient (two criteria): Non-urgent: lower self-perception of urgency (in 5 levels) or patient agreed to schedule MD appointment within 1-3 days

- According to nurse triage (2 criteria): 4 -point scale: category 4 was avoidable consultations

- According to medical record (three criteria): when not necessary to hospitalize, perform diagnostic tests, or special treatment (e.g.: IV medication, O2), and could wait $>24$ hours to be evaluated and treated

\section{Classified as urgent or non-urgent:}

- Non-urgent: presence of vital signs within normal limits, presence of non-urgent complaints, complementary tests without important alterations, and no indication of high risk. After triage, these patients were referred for outpatient care without ED consultation

Classified as urgent and non-urgent: - Urgent: patient's self-perceived urgency

Classification as urgent and non-urgent:

- Urgent: when the professional felt there was risk of death, need for treatment within few hours to prevent severe complications

- Non-urgent: all other situations

Classified as urgent and non-urgent:

- Urgent: resulted in hospitalization, referred by another health service, or came from accidents, signs and symptoms suggesting severity, < 16 years (with no accompanying person), and suspicion of sexual abuse

- Non-urgent: other cases

- Urgent: altered vital signs, acute chest pain (with cardiac risk factor), acute asthma ( $<1$ week), acute abdominal pain

(with associated risk factors).

- Non-urgent: all other situations

Classified in 3 levels: Emergency, urgency, and non-urgency - Non-urgent: patient could wait until next day (> 12 hours) to receive treatment, according to nurses, depending on vital signs and brief evaluation to discard urgent conditions.
$37.1 \%$

20 to $37 \%$ in 5 criteria; $90 \%$ hospitalization criterion; $10 \%$ selfperceived urgency criterion

$18 \%$

(continues) 
Article

Protocol
Country
Prevalence of inappropriate use

\section{North America}

Liu et al. 30

USA

1999

Sarver et al. 25

USA

2002

Billings et al. 18

USA

2000 risk of death or functional injuries.

- Non-urgent: other situations primary care; emergency requiring $\mathrm{ED}$, although prevented or avoided; and emergency requiring ED and could not be prevented or avoided.

- Non-urgent: complaint not requiring immediate medical care ( $<12$ hours)

Classified in 4 levels: non-urgent; urgent for primary care; urgent that required $\mathrm{ED}$, but could be prevented and treated; and emergency.

- Non-urgent: situations in which evaluation and treatment could take more than 12 hours

Classified in 5 levels: emergency, urgent, semi-urgent, nonurgent, and unknown or not triaged:

- Non-urgent: situation not requiring immediate attention, could be evaluated in 2-24 hours

- Category 3 (non-urgent): when no need to receive immediate care, within 20 minutes, not referred by a health professional, did not require urgent investigation or treatment, did not require remaining in observation, absence of acute and severe situation or without need to perform differential diagnosis, could wait for $>6$ hours to be evaluated in the ED or other health service.

Classified in 3 levels: emergency, urgent, and non-urgent:

- Non-urgent: did not require medical intervention within require resources only available in the ED.

(continues) 
Table 1 (continued)

\begin{tabular}{|c|c|c|c|c|c|}
\hline Article & Protocol & Country & $\begin{array}{c}\text { Year of } \\
\text { publication }\end{array}$ & Criterion & $\begin{array}{c}\text { Prevalence of } \\
\text { inappropriate use }\end{array}$ \\
\hline
\end{tabular}

\section{North America}

Afilalo et al. 12

CTAS Criterion

Canada

Fajardo-Ortiz \&

Mexico

Ramirez-Fernandez

28

\section{Europe}

Dale et al. 19

UK

1995

Coleman et al. 33

Oterino et al. 14

PAUH

Spain

1999

Sempere-

Selva et al. 16

Sánchez-

López et al. 15

PAUH

Modified PAUH

Spain

2004
2000

2004 evaluated, frequency with which patient could be evaluated while waiting to be seen, and presence of complication (altered vital signs, level of pain, and mechanism of injury,

$$
\text { e.g., car accident). }
$$

- Level 5 (Non-urgent): patient could wait 2 hours to be seen by MD without risk of death and could be investigated

or receive intervention elsewhere in the health system

$$
\text { Classified as true urgency or not: }
$$

- True urgency: after medical evaluation, the patient presented indication of remaining in hospital for 24 hours, need for surgery, ICU or death.

- Non-urgent: other situations

$25 \%$
- Non-urgent: came by themselves, could be resolved by primary care, no need for immediate intervention.

Classified as urgent or non-urgent:

- Non-urgent: patients with non-urgent injuries or diseases that could be treated elsewhere.

Classified as true urgency or not:

$26,8 \%$

- Urgent: criteria for severity of signs and symptoms, treatment, diagnoses, related to follow-up on consultation and extra criteria for patient not referred by MD.

- Non-urgent: did not meet any of the above criteria.

$$
\text { Classified as urgent or not: }
$$

- Urgent: criteria for severity of signs and symptoms, treatment, diagnoses, related to follow-up on consultation and extra criteria for patient not referred by MD.

- Non-urgent: when did not meet any of the above criteria.

- Urgent: criteria for severity of signs and symptoms, treatment, diagnoses (excluded X-ray), related to follow-up on consultation and extra criteria for patient not referred by $\mathrm{MD}$.

- Non-urgent: did not meet any of the above criteria.

\section{Classified as appropriate or not:}

- Appropriate: resulted in hospitalization, death, was transferred to another hospital, or explicit criteria based on diagnostic tests or specific treatments (modified, excluding chest X-ray)

- Inappropriate: other situations.

(continues) 
Table 1 (continued)

\begin{tabular}{|c|c|c|c|c|}
\hline Article & Protocol & $\begin{array}{ll}\text { Country } & \begin{array}{c}\text { Year of } \\
\text { publication }\end{array}\end{array}$ & Criterion & $\begin{array}{c}\text { Prevalence of } \\
\text { inappropriate use }\end{array}$ \\
\hline
\end{tabular}

Europe

\begin{tabular}{|c|c|c|c|c|}
\hline Oktay et al. 21 & Based on CTAS & Turkey & 2003 & $\begin{array}{l}\text { Classified in } 3 \text { levels: emergency, urgent, and non-urgent. } \\
\text { - Non-urgent: patient that could be evaluated in the ED or } \\
\text { elsewhere after more than } 6 \text { hours without risk of death. }\end{array}$ \\
\hline Bianco et al. 37 & $\begin{array}{c}\text { Based on other } \\
\text { studies }\end{array}$ & Italy & 2003 & $\begin{array}{l}\text { Classified in } 4 \text { levels: extreme emergency, emergency, } \\
\text { emergency as perceived by patient, and non-urgent. } \\
\text { - Non-urgent: patient with no acute symptoms or the latter } \\
\text { were recent and minor, without self-perceived emergency, } \\
\text { wishing to have a check-up, renew a prescription, or excuse }\end{array}$ \\
\hline
\end{tabular}

Asia

Shah et al. 31

Lee et al. 32

China

Rodríguez et al. 23

Dent et al. 27

Based on Australian Triage Scale (ATS)

Finn et al. 40 2001

Cuba

Australia

2003
Stein et al. 26

Protocol for evaluation of

urgency

Australia

evaluation
urgency

Brazilian Federal Board of Medicine + dictionary

$$
\text { Brazil } 2002
$$
to return to work.
2000

1996

Classified in 4 levels: emergency, urgent, marginally urgent

$$
\text { and non-urgent. }
$$

- Non-urgent: in MD's assessment, did not present risk of death or did not require care within hours to decrease

$$
\text { discomfort. }
$$

Classified as true urgency or not:

$57 \%$

- Non-urgent: could be managed as outpatients by GP, could wait several hours to be seen without risk of death or harm to patient.

$$
\text { and non-urgent. }
$$

- Non-urgent: chronic disease problems, not acute-onchronic, no risk of death in their evolution, could wait 24-48 hours to be treated by family doctor.

Classified as appropriate or inappropriate:

- Appropriate: when referred by health professional classified from 1 to 3 on the Australian scale, required $\geq 4$ hours of treatment or observation, was hospitalized or died, arrived between 10:00PM and 07:00AM.

- Inappropriate (treatable by GP): other situations

$$
\text { Classified as appropriate or not: }
$$

- Appropriate: could not be evaluated or managed by primary care or at patient's home. By definition, whenever patient was hospitalized, consider appropriate.

- Inappropriate: all other situations

Classified in 3 levels: emergency, urgent, and non-urgent.

- Elective consultation in ED: when could

(continues) 
Table 1 (continued)

\begin{tabular}{|c|c|c|c|c|c|}
\hline Article & Protocol & Country & $\begin{array}{c}\text { Year of } \\
\text { publication }\end{array}$ & Criterion & $\begin{array}{c}\text { Prevalence of } \\
\text { inappropriate use }\end{array}$ \\
\hline Carret et al. 13 & PAUH & Brazil & 2007 & Classified as urgent or not: & $24.2 \%$ \\
\hline & & & & $\begin{array}{l}\text { - Urgent: criteria for severity of signs and symptoms, } \\
\text { treatment, diagnoses, related to follow-up of consultation } \\
\text { and extra criteria for patient not referred by MD. } \\
\text { - Non-urgent: did not meet any of the above criteria. }\end{array}$ & \\
\hline
\end{tabular}

ED: emergency department; CTAS: Canadian Triage and Acuity Scale; PAUH: Hospital Urgencies Appropriateness Protocol; MD: Doctor of Medicine;

GP: general practitioner.

The three studies that evaluated the association between means of transportation $12,16,26$ and inappropriate use found varied results, which can be explained by the variation in each site's characteristics (size of the city, population's socioeconomic status, quality of mass transportation, and availability of ambulance services, among others). The majority of the studies that investigated proximity to the ED did not show a significant association with inappropriate use 14,16,32,37. However, according to Oktay et al. 21, proximity to the ED was the principal reason for inappropriate complaints. Likewise, Young et al. ${ }^{35}$ found that distance was one of the barriers to utilization of primary health care by individuals that visited the ED inappropriately.

\section{Demographic variables}

Sixteen studies showed an inverse association between age and inappropriate ED use 12,13,14,16, $19,21,22,23,25,30,31,32,33,34,37,42$. Only two studies 40,43 failed to show this association. In the first, the study population consisted of adults 65 years or older; the second, in addition to only comparing mean age in two groups, showed a lower score based on the Downs \& Black criteria.

The association with gender was evaluated in 16 studies, eight of which 13,14,21,22,25,30,34,37 observed (in the multivariate analysis) that women showed higher odds of inappropriately visiting the ED. In the studies, the RR varied from 1.12 to 1.56. Carret et al. 13 stratified their sample in two age groups and only found this association in the younger groups (15-49 years) $(\mathrm{RR}=1.52$, $\mathrm{p}<0.001$ )

Among those not showing an association with gender 12,16,19,23,31,32,40,43, five 16,19,23,31,43 only performed univariate analysis and/or showed a low score according to Downs \& Black criteria and Finn et al only studied individuals 65 years or older ${ }^{40}$. Two other studies that did not show an association with gender were case-controls; however, they compared populations with similar health problems that chose to go to the ED or to the outpatient department, while the others compared individuals with inappropriate versus appropriate ED use 12,32. The study by Shah et al. 31 was performed in Kuwait, where important cultural differences could explain this lack of association.

Of six studies that evaluated marital status $12,13,16,31,34,37$, only Afilalo et al. 12 showed an association between living alone and appropriate ED use $(p=0.046)$. Five studies examined race or skin color, but since they categorized it differently it was impossible to summarize the results $13,25,30,34,43$.

\section{Socioeconomic variables}

Three studies found a direct association between socioeconomic status (schooling 22,31 and income 21) and inappropriate ED use 21,22,31. Bianco et al. 37 showed a borderline direct association between schooling and inappropriate ED use ( $p=0.052$ ), as did Carret et al. 13 for the group 50 years or older $(p=0.06)$. Lee et al. 32 found no association between schooling and inappropriate use, but individuals that owned their own homes used the ED more inappropriately than those that consulted primary care for similar complaints.

Three studies found no association between socioeconomic status and the outcome 12,26,34, but Petersen et al. 34 compared groups with more (versus less) than 12 years of schooling and Afilalo et al. 12 only performed a univariate analysis for this association. Meanwhile, Sarver et al. 25, in a cohort study of a population that reported having a regular non-emergency source of care showed an inverse relationship between income and inappropriate ED use.

In most of the studies, occupational status was not associated with inappropriate ED use 
Characteristics of studies that evaluated factors associated with inappropriate use of the emergency department (ED).

\begin{tabular}{|c|c|c|c|c|c|c|c|}
\hline Article & $\begin{array}{c}\text { Year of } \\
\text { publication }\end{array}$ & Country & Design & Sample & Field period & Associated factors & Score * \\
\hline Baker et al. 45 & 1995 & USA & $\begin{array}{l}\text { Cross- } \\
\text { sectional }\end{array}$ & $\begin{array}{l}\mathrm{N}=1,190 \\
\text { (adults that } \\
\text { arrived } \\
\text { between } \\
\text { 7:00AM and } \\
\text { 11:00PM) }\end{array}$ & $\begin{array}{c}2 \text { weeks } \\
\text { (spring/1990) }\end{array}$ & $\begin{array}{l}\text { No difference as to coming to ED on own, although } \\
\text { those seen previously by MD and not referred } \\
\text { showed more inappropriate ED use }(p<0.05) \text {. }\end{array}$ & 6 \\
\hline Young et al. 35 & 1996 & USA & $\begin{array}{l}\text { Cross- } \\
\text { sectional, } \\
\text { multi- } \\
\text { center }\end{array}$ & $\begin{array}{c}\mathrm{N}=6,187 \\
\text { (patients with } \\
\text { non-urgent } \\
\text { complaints) }\end{array}$ & $\begin{array}{c}24 \text { hours (June } \\
\text { 1994) }\end{array}$ & $\begin{array}{l}\text { Characteristics of demand: } 39 \% \text { self-reported } \\
\text { urgent, } 21 \% \text { preferred ED due to better care } \\
\text { or possibility of diagnosis and treatment, } 50 \% \\
\text { reported non-financial barriers (primary care closed, } \\
\text { nowhere else to go, difficulty or delay scheduling } \\
\text { appointment, distance, transportation problems), } \\
\text { and } 15 \% \text { reported financial barriers (no money } \\
\text { or insurance, ED free or cheaper, required by } \\
\text { insurance company, insurance paid for ED care). } \\
\text { RFA: univariate: regular source of care ( } p<0.001 \text { ), } \\
\text { referred by health professional ( } p<0.001) \text {. No } \\
\text { difference between complaints. }\end{array}$ & 7.5 \\
\hline $\begin{array}{l}\text { Petersen } \\
\text { et al. } 34\end{array}$ & 1998 & USA & $\begin{array}{c}\text { Cross- } \\
\text { sectional }\end{array}$ & $\begin{array}{c}\mathrm{N}=1.696 \\
(\geq 16 \text { years; } \\
\text { with chest pain, } \\
\text { abdominal } \\
\text { pain, and } \\
\text { asthma) }\end{array}$ & $\begin{array}{c}\text { one month in } \\
\text { each ED (1993) }\end{array}$ & 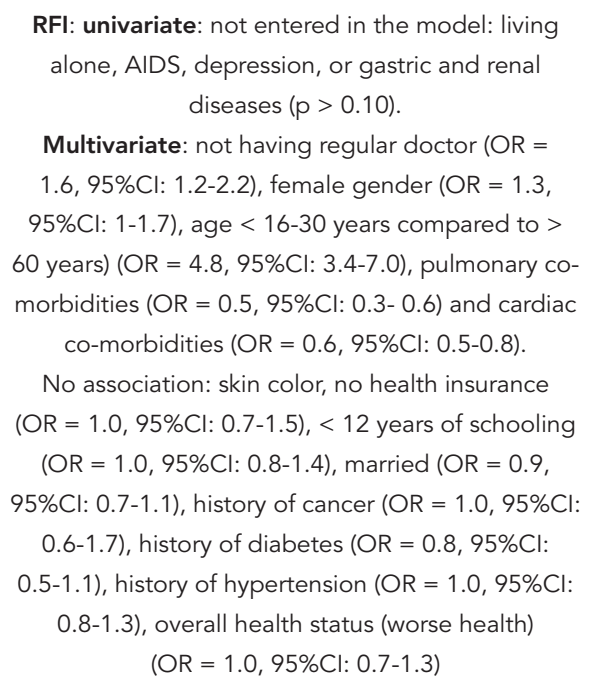 & 8 \\
\hline
\end{tabular}

(continues)

12,13,25,34,43. Lee et al. 32 showed protection against inappropriate use for individuals that worked part-time and for housewives, compared to those that worked fulltime. Pereira et al. 22 observed that retired women visited the ED 70\% more appropriately than wage-earning women, even after adjusting for age.

\section{Health needs}

Some authors have reported that individuals without chronic non-communicable diseases or co-morbidities visit the ED more inappropriately $12,14,40$, while others have found the same in a specific age group (50 years and older) 13 or in persons without specific co-morbidities (cardiac and pulmonary) 34 . The magnitude of the asso- 


\begin{tabular}{|c|c|c|c|c|c|c|c|}
\hline Article & $\begin{array}{c}\text { Year of } \\
\text { publication }\end{array}$ & Country & Design & Sample & Field period & Associated factors & Score * \\
\hline Liu et al. 30 & 1999 & USA & $\begin{array}{c}\text { Cross- } \\
\text { sectional }\end{array}$ & $N=135,723$ & $1992-1996$ & $\begin{array}{l}\text { RFI: multivariate: } \geq 65 \text { years }(\mathrm{OR}=0.56,95 \% \mathrm{Cl} \text { : } \\
\text { 0.53-0.58), men (OR }=0.89,95 \% \mathrm{Cl}: 0.87-0.91) \text {, } \\
\text { non-white ( } p=0.001) \text {, place of residence }(p< \\
\text { 0.001), urban area (OR }=0.95,95 \% \mathrm{Cl}: 0.87-0.93) \\
\text { Diagnoses (comparison group: injuries and } \\
\text { poisonings): diseases of the nervous system and } \\
\text { sensory organs ( } \mathrm{OR}=1.85,95 \% \mathrm{Cl}: 1.76-1.94) \text {, } \\
\text { respiratory diseases (OR }=1.17,95 \% \mathrm{Cl}: 1.13-1.22) \\
\text { and diseases of the digestive system } \\
(\mathrm{OR}=1.14,95 \% \mathrm{Cl}: 1.09-1.20) \text {. } \\
\text { As to health insurance: compared to private: } \\
\text { Medicare (OR }=0.75,95 \% \mathrm{Cl}: 0.72-0.79), \text { Medicaid } \\
(\mathrm{OR}=1.14, \mathrm{IC} 19 \%: 1.11-1.18), \mathrm{HMO} \\
(\mathrm{OR}=1.02,95 \% \mathrm{Cl}: 0.98-1.06), \text { other } \\
(\mathrm{OR}=1.06,95 \% \mathrm{Cl}: 1.03-1.09)\end{array}$ & 13 \\
\hline Sarver et al. 25 & 2002 & USA & Cohort & $\begin{array}{l}\mathrm{N}=9,146 \\
(\geq 18 \text { years, that } \\
\text { reported having } \\
\text { a regular source } \\
\text { of care, not } \\
\text { ED, and that } \\
\text { had at least } \\
\text { one contact } \\
\text { in } 1996 \text { or did } \\
\text { not succeed in } \\
\text { consulting their } \\
\text { primary care) }\end{array}$ & 2 years (1996) & 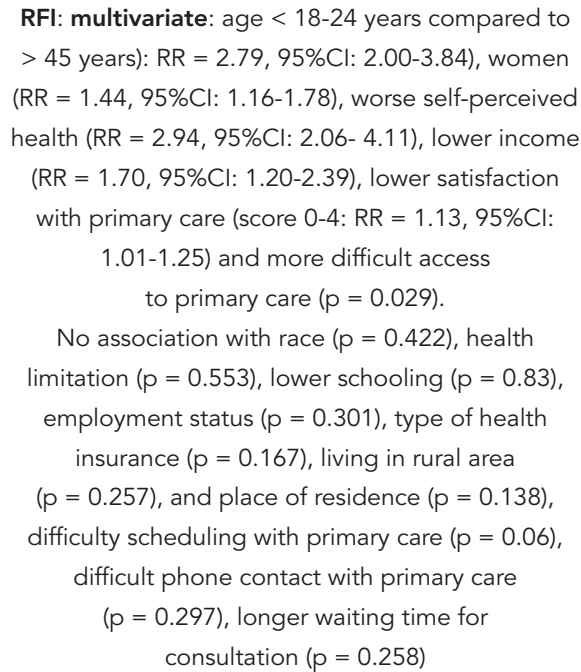 & 12 \\
\hline
\end{tabular}

(continues)

ciation varied from 1.5 to 2.0. Meanwhile, Bianco et al. 37 and Carret et al. ${ }^{13}$, among adults younger than 50 years, and Peterson et al. ${ }^{34}$, studying other co-morbidities (cancer, diabetes mellitus, systemic arterial hypertension), found no association with inappropriate ED use.

In relation to self-perceived health, three authors 12,13,34 found no association with the outcome. However, Sarver et al. 25 pointed out that individuals with worse self-perceived health had nearly three times more inappropriate ED visits than those with good to excellent self-perceived health, but in this case self-perceived health was assessed outside the ED.

\section{Access to health services}

\section{- Cost and form of payment for care}

According to three authors, cost of the consultation was associated with inappropriate use. Oktay et al. 21 found that those who paid for the consultation used the ED 60\% more appropriately than those who did not pay. Lee et al. 32 attributed the preference for using primary care (rather than the ED) for outpatient complaints to the lower cost of primary care, while Young et al. 35 ascribed higher inappropriate ED use to the fact that it cost less. 


\begin{tabular}{|c|c|c|c|c|c|c|c|}
\hline Article & $\begin{array}{c}\text { Year of } \\
\text { publication }\end{array}$ & Country & Design & Sample & Field period & Associated factors & Score * \\
\hline Afilalo et al. 12 & 2004 & Canada & $\begin{array}{c}\text { Cross- } \\
\text { sectional }\end{array}$ & $\begin{array}{c}N=1,783 \\
(\geq 18 \text { years })\end{array}$ & $\begin{array}{l}\text { October } 1999 \\
\text { to May } 2000\end{array}$ & $\begin{array}{l}\text { RFI: univariate: older ( } p=0.01) \text {, live less alone ( } p= \\
\text { 0.045), visited less after hours ( } 4: 00 P M-08: 00 A M) \text {, } \\
\text { came to ED less by ambulance ( } p=0.0026) \text {, less } \\
\text { self-perceived urgency ( } p=0.0067) \text {, better self- } \\
\text { perceived overall health ( } p=0.016) \text {, fewer co- } \\
\text { morbidities ( } p=0.023) \text {, and less hospitalization in } \\
\text { previous } 3 \text { years ( } p=0.0029) \text {, took longer to come } \\
\text { to ED. No difference in gender, schooling, marital } \\
\text { status, immigration, employment status, day of } \\
\text { week, being followed by primary care or specialist. } \\
\text { Most frequent complaints among non-urgent ED } \\
\text { users: abdominal pain and chest pain. } \\
\text { Reasons for ED rather than primary care: ease } \\
\text { of access ( } 32 \%) \text {, trust ( } 7 \% \text { ) familiarity (11\%), and no } \\
\quad \text { reason ( } 7 \%) \text {. } \\
\text { RFI: comparing the } 5 \text { hospitals. } \\
\text { Multivariate: (after adjusting for age, income, } \\
\text { number of beds, and urban area, compared } \\
\text { different hospitals): only visit during business hours, } \\
\text { less use of ambulance, and lower self-perception of } \\
\text { urgency were associated with non-urgency (results } \\
\text { same as univariate) }\end{array}$ & 10 \\
\hline $\begin{array}{l}\text { Fajardo-Ortiz } \\
\text { \& Ramirez- } \\
\text { Fernández } 28\end{array}$ & 2000 & Mexico & $\begin{array}{c}\text { Cross- } \\
\text { sectional }\end{array}$ & $\begin{array}{l}N=26,005 \\
(\geq 15 \text { years })\end{array}$ & 1 year (1996) & $\begin{array}{l}\text { Ratio between real urgency and non-urgent: } \\
\text { 9:00PM-7:59AM (ratio = 1/0.95), 8:00AM-2:29PM } \\
\text { (ratio = 1/1.39), 2:30-8:59PM (ratio = 1/1.87), and } \\
\text { 8:00AM-8:59PM Saturday, and 08:00AM Sunday- } \\
\text { 07:59AM Monday (ratio }=1 / 3.31 \text { ) }\end{array}$ & 6 \\
\hline Dale et al. 19 & 1995 & UK & $\begin{array}{c}\text { Cross- } \\
\text { sectional }\end{array}$ & $\begin{array}{c}\mathrm{N}=2,648 \\
\text { (patients of all } \\
\text { ages) }\end{array}$ & $\begin{array}{l}1 \text { year (June } \\
1989 \text { to May } \\
\text { 1990) }\end{array}$ & 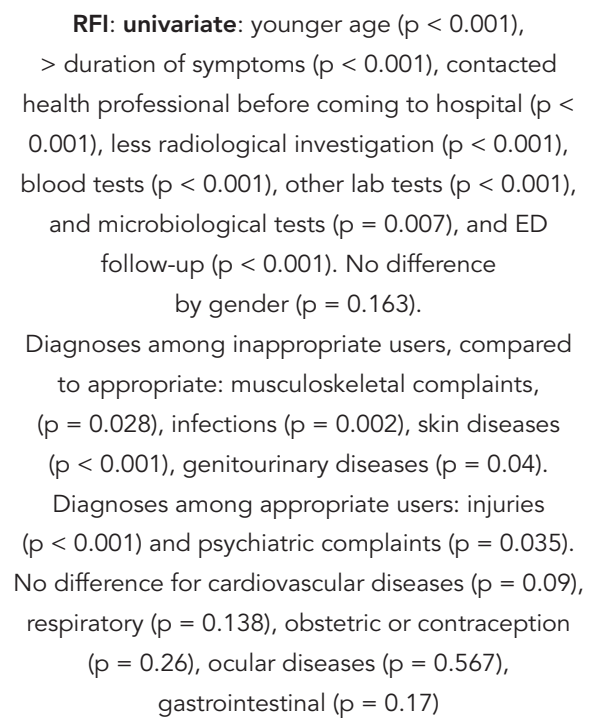 & 7 \\
\hline
\end{tabular}

(continues) 


\begin{tabular}{|c|c|c|c|c|c|c|c|}
\hline Article & $\begin{array}{c}\text { Year of } \\
\text { publication }\end{array}$ & Country & Design & Sample & Field period & Associated factors & Score * \\
\hline Rajpar et al. 43 & 2000 & UK & $\begin{array}{l}\text { Case- } \\
\text { control }\end{array}$ & $\begin{array}{c}\mathrm{N}=54 \text { non- } \\
\text { urgent ED } \\
\text { patients and } 48 \\
\text { outpatients, off } \\
\text { hours, all ages) }\end{array}$ & $\begin{array}{l}12 \text { three-hour } \\
\text { sections }\end{array}$ & $\begin{array}{l}\text { RF for seeking ED rather than primary care: } \\
\text { whites (compared to Asians) }(p<0.01 \text { ) and } \\
\text { younger. No difference by gender, employment } \\
\text { status ( } p>0.05) \text {. } \\
\text { Not significant difference for mean age } \\
(0-80 \text { years); but when observed by age brackets, } \\
\text { the 21-40- year group used the ED the most for } \\
\text { off-hours primary care consultations. } \\
\text { Reasons for using ED inappropriately (among } 54 \\
\text { patients): primary care closed ( } 50 \%) \text {, but } 46.3 \% \text { did } \\
\text { not even attempt contact with primary care and } \\
22 \% \text { perceived situation as urgent. }\end{array}$ & 5 \\
\hline $\begin{array}{l}\text { Coleman } \\
\text { et al. } 33\end{array}$ & 2001 & UK & $\begin{array}{c}\text { Cross- } \\
\text { sectional }\end{array}$ & $\begin{array}{l}\mathrm{N}=255 \text { (adults } \\
\text { with green and } \\
\text { yellow cards) }\end{array}$ & $\begin{array}{l}7 \text { weeks } \\
\text { (October- } \\
\text { December } \\
\text { 1997) }\end{array}$ & $\begin{array}{l}\text { Characteristics of non-urgent patients: mean } 34 \\
\text { years, } 81 \% \text { self-referred, } 80 \% \text { trauma, } 20 \% \\
\text { non-trauma, } 1 / 4 \text { of problems occurred at home, } \\
2 / 3 \text { came from home. } \\
\text { Main reason for visiting ED: believe they needed } \\
\text { X-ray and to be oriented by someone. }\end{array}$ & 8 \\
\hline $\begin{array}{l}\text { Oterino } \\
\text { et al. } 14\end{array}$ & 1999 & Spain & $\begin{array}{c}\text { Cross- } \\
\text { sectional }\end{array}$ & $\begin{array}{c}N=1,845 \\
(\geq 15 \text { years })\end{array}$ & 1 year (1996) & 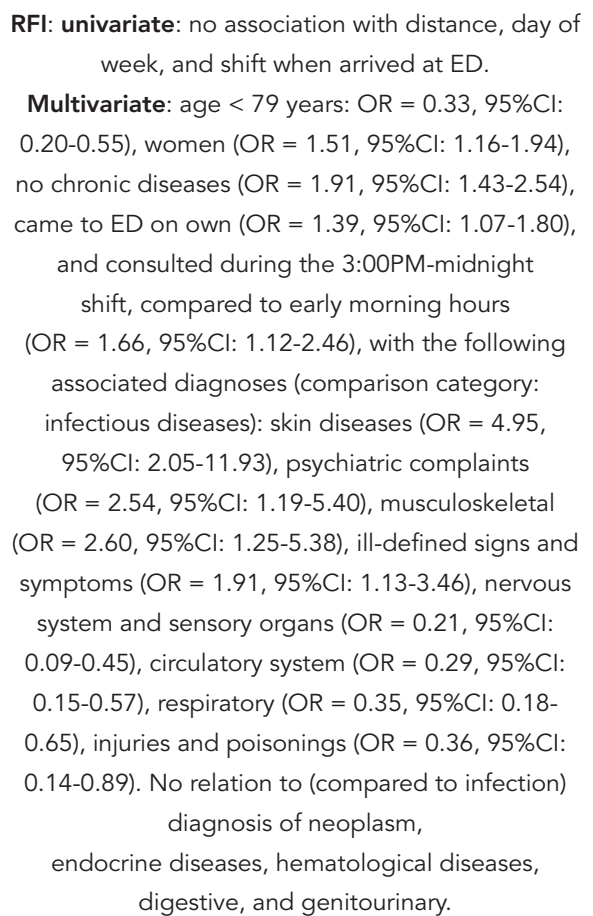 & 9 \\
\hline
\end{tabular}

After adjusting for possible confounding factors, four studies 13,22,25,34 found no association between not having a health plan and inappropriate ED use, two of which 13,22 were conducted in countries with public health care systems and two in countries without such a system 25,34 . Liu et al. 30 found varied associations, depending on the person's type of insurance. 


\begin{tabular}{|c|c|c|c|c|c|c|c|}
\hline Article & $\begin{array}{c}\text { Year of } \\
\text { publication }\end{array}$ & Country & Design & Sample & Field period & Associated factors & Score * \\
\hline $\begin{array}{l}\text { Sempere-Selva } \\
\text { et al. } 16\end{array}$ & 2001 & Spain & $\begin{array}{l}\text { Cross- } \\
\text { sectional }\end{array}$ & $N=2,980$ & $\begin{array}{l}1 \text { year (May } \\
1996 \text { to } \\
\text { April 1997) }\end{array}$ & $\begin{array}{l}\text { RFI: univariate: younger age, came by car, } \\
\text { referred by hospital, reside in specific areas of the } \\
\text { city, certain months of the year, were out of their } \\
\text { area of consultation. No association with gender, } \\
\text { living alone, distance from hospital, referred by } \\
\text { health professional, or came on own. } \\
\text { Symptoms: principally ocular, allergic } \\
\text { reactions, conjunctivitis, hearing and } \\
\text { other sensory complaints. } \\
\text { Among inappropriate ED users, } 16 \% \\
\text { had been referred by MD. } \\
\text { Among inappropriate users who came on own, } \\
9.4 \% \text { reported difficulty in obtaining access to } \\
\text { other services, } 9 \% \text { due to lack of information on } \\
\text { alternative sources of care. Main reason was greater } \\
\text { trust in ED than in primary care. }\end{array}$ & 9.5 \\
\hline $\begin{array}{l}\text { Pereira. } \\
\text { et al. } 22\end{array}$ & 2001 & Portugal & $\begin{array}{l}\text { Cross- } \\
\text { sectional }\end{array}$ & $\begin{array}{l}N=5,818 \\
(\geq 13 \text { years })\end{array}$ & $\begin{array}{c}12 \text { days } \\
\text { (February-June } \\
\text { 1998) }\end{array}$ & $\begin{array}{l}\text { RFA: univariate: men (OR }=1.28,95 \% \mathrm{Cl} \text { : } \\
\text { 1.14/1.44, } p<0.001) \text { and all in multivariate. } \\
\text { No association with "kind of insurance" } \\
(p=0.465) \text { or day of week ( } p=0.814) \text {. } \\
\text { Multivariate: gender had modifying effect } \\
\text { (interaction with having job, schooling, and } \\
\text { duration of symptoms). Women: } \geq 60 \text { years } \\
(\mathrm{OR}=1.7,95 \% \mathrm{Cl}: 1.0-2.9) \text {, retired compared to } \\
\text { wage-earning (OR }=1.7,95 \% \mathrm{Cl}: 1.0-2.7) \text {, visits } \\
\text { from midnight to } 08: 00 \mathrm{AM}(\mathrm{OR}=2.5,95 \% \mathrm{Cl} \text { : } \\
1.4 / 5.4) \text { symptoms } \leq 24 \text { hours } \\
(\mathrm{OR}=2.7,95 \% \mathrm{Cl}: 2.1-3.7) \text {. } \\
\text { Men: } \geq 60 \text { years (OR }=2.3,95 \% \mathrm{Cl} ; 1.5-3.9) \text {, } \\
\text { symptoms } \leq 24 \text { hours }(\mathrm{OR}=4.0,95 \% \mathrm{Cl}: 2.9-5.3)\end{array}$ & 12 \\
\hline Bianco et al. 37 & 2003 & Italy & $\begin{array}{l}\text { Cross- } \\
\text { sectional }\end{array}$ & $\begin{array}{c}N=541 \\
(\geq 15 \text { years })\end{array}$ & $\begin{array}{c}2 \text { weeks + } \\
1 \text { weekend, } \\
\text { 08:30AM- } \\
\text { 02:00PM and } \\
\text { 03:00-07:00PM } \\
\text { (July-December } \\
\text { 2001) }\end{array}$ & $\begin{array}{c}\text { RFI: univariate: No difference in gender } \\
(p=0.12) \text {, marital status }(p=0.15) \text {, schooling } \\
(p=0.89) \text {, number of persons per household } \\
(p=0.5) \text {, distance from home to ED }(p=0.052) \text {, } \\
\text { presence of chronic non-communicable } \\
\text { diseases }(p=0.09) \text {, day of week }(p=0.18) \text {, } \\
\text { time of arrival at ED }(p=0.94) \text {. } \\
\text { Multivariate: younger age }(p<0.001) \text {, women } \\
(O R=1.56,95 \% C l: 1.0-2.51) \text {, not referred by } \\
\text { physician (OR }=2.42,95 \% C l: 1.13-5.16) \text {, longer } \\
\quad \text { duration of symptoms } \\
(O R=1.78,95 \% C l: 1.23-2.58) \text {. } \\
\text { No relationship to schooling (does not specify } \\
\text { direction, } p=0.052) \text {, number of persons in } \\
\text { household ( } p=0.357) \text {, distance from home to ED } \\
(p=0.39) \text {, chronic non-communicable disease } \\
(p=0.376) \text {, day of week ( } p=0.258)\end{array}$ & 10 \\
\hline
\end{tabular}

(continues) 


\begin{tabular}{|c|c|c|c|c|c|c|c|}
\hline Article & $\begin{array}{c}\text { Year of } \\
\text { publication }\end{array}$ & Country & Design & Sample & Field period & Associated factors & Score * \\
\hline Oktay et al. 21 & 2003 & Turkey & $\begin{array}{l}\text { Cross- } \\
\text { sectional }\end{array}$ & $\begin{array}{c}N=1,155 \\
(17-99 \text { years })\end{array}$ & $\begin{array}{c}14 \text { days } \\
\text { (November } \\
\text { 1998) }\end{array}$ & 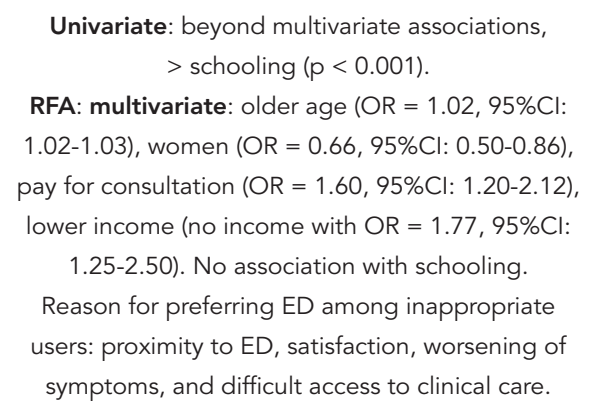 & 10 \\
\hline Shah et al. 31 & 1996 & Kuwait & $\begin{array}{l}\text { Cross- } \\
\text { sectional }\end{array}$ & $\begin{array}{c}N=2,011 \\
(6 \mathrm{EDs})\end{array}$ & $\begin{array}{c}\text { 07:30AM- } \\
\text { 09:00PM } \\
\text { (January- } \\
\text { February 1993) }\end{array}$ & 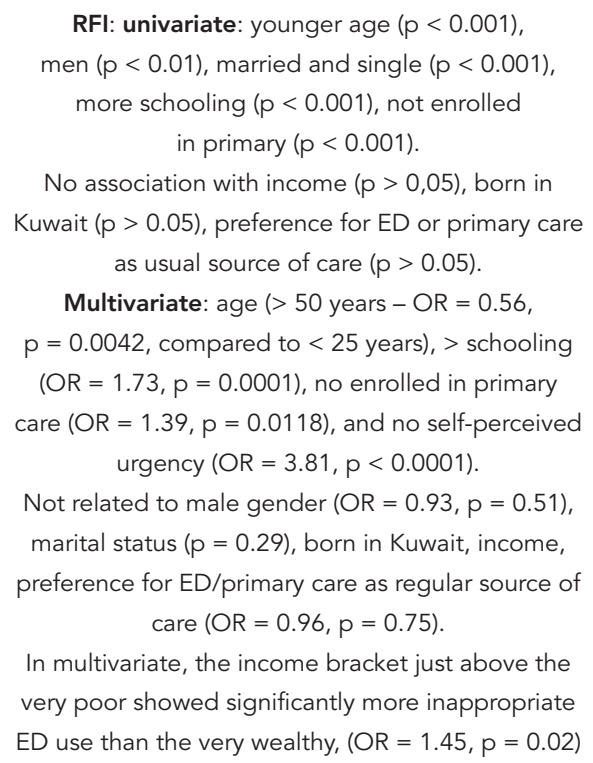 & 8 \\
\hline Lee et al. 42 & 2001 & China & $\begin{array}{c}\text { Cross- } \\
\text { sectional }\end{array}$ & $\begin{array}{c}N=2,410 \\
(4 \mathrm{EDs})\end{array}$ & 1 year (1997) & $\begin{array}{l}\text { RFI: univariate: }<\text { age }(p<0.001) \text {. No significant } \\
\text { difference in time of arrival at ED. The article later } \\
\text { concludes that the highest inappropriate use rates } \\
\text { occur in late afternoon and early morning. } \\
\text { Principal causes of inappropriate use were } \\
\text { respiratory complaints (principally in younger } \\
\text { patients) and digestive complaints. }\end{array}$ & 8 \\
\hline
\end{tabular}

\section{- Regular physician and regular health care facility}

In two studies, individuals with a regular physician showed 40 and $67 \%$ less inappropriate ED use, respectively 26,34 . In the same sense, two other studies showed that individuals with a link to primary health care used the ED more appropriately 31,35 . However, four studies found no such associations for regular physician 13,32 or regular source of care 12,13,26. This lack of association may be related to the more rigorous criteria for defining inappropriate use 12,13 and the low precision of the multivariate analysis, suggested by wide confidence intervals found in one of the studies 32 . In addition, aspects not shown in the data analysis could explain the fact that Stein et al. 26 found an association between the outcome and regular physician, but not with regular source of care, such as colinearity between these two variables if they were evaluated at the same time in the analysis. 


\begin{tabular}{|c|c|c|c|c|c|c|c|}
\hline Article & $\begin{array}{c}\text { Year of } \\
\text { publication }\end{array}$ & Country & Design & Sample & Field period & Associated factors & Score * \\
\hline Lee et al. 32 & 2000 & China & $\begin{array}{l}\text { Case- } \\
\text { control }\end{array}$ & $\begin{array}{l}726 \text { cases } \\
\text { (4 EDs) and } \\
726 \text { controls } \\
\text { (2 outpatient } \\
\text { services) }\end{array}$ & 1 year (1997) & $\begin{array}{l}\text { RFI: univariate: younger age and proximity too ED } \\
\quad(p<0.01) \text {. No difference in gender }(p=0.2) . \\
\text { Case-control: } \\
\text { Variables evaluated: own home, schooling, regular } \\
\text { doctor, occupational status, reasons for non-urgent } \\
\text { patients to prefer ED to primary care. } \\
\text { Multivariate: age } 0-9 \text { years compared to } \geq 65 \text { years } \\
\text { (OR }=5.44,95 \% \mathrm{Cl}: 1.6-18.2) \text {, part-time workers or } \\
\text { housewives (OR }=0.38,95 \% \mathrm{Cl}: 0.19-0.78) \text {. } \\
\text { Reasons for preferring ED to primary care: greater } \\
\text { efficiency in diagnosis, greater self-perceived } \\
\text { urgency, primary care closed, desperate for } \\
\text { help. Lower cost associated with lower odds of } \\
\text { inappropriate ED use. } \\
\text { No association with proximity to ED }\end{array}$ & 13 \\
\hline Finn et al. 40 & 2006 & Australia & $\begin{array}{l}\text { Cross- } \\
\text { sectional }\end{array}$ & $\begin{array}{l}\quad N=541 \\
(\geq 65 \text { years, } \\
\text { living in homes } \\
\text { for elderly) }\end{array}$ & $\begin{array}{c}\text { January } 1 \text { st } \\
\text { to June } 30 \text { rd, } \\
2002\end{array}$ & $\begin{array}{l}\text { RFA: multivariate: prior consultation with primary } \\
\text { care physician or substitute physician }(p=0.02) \text {, } \\
\text { more clinical interventions, longer time in ED } \\
\quad(p<0.001) \text {, lower survival rate }(p=0.02) \text {. } \\
\text { No difference: age }(p=0,93) \text {, gender }(p=0.96)\end{array}$ & 8 \\
\hline $\begin{array}{l}\text { Rodríguez } \\
\text { et al. } 23\end{array}$ & 2001 & Cuba & $\begin{array}{l}\text { Cross- } \\
\text { sectional }\end{array}$ & $\begin{array}{l}\quad N=1,360 \\
(\geq 15 \text { years, ED } \\
\text { and polyclinic) }\end{array}$ & 5 days (1995) & $\begin{array}{c}\text { RFI: univariate: younger age }(p<0.001) \\
\text { business hours }(p<0.001) \\
\text { No difference in gender }(p>0.05)\end{array}$ & 7.5 \\
\hline Stein et al. 26 & 2002 & Brazil & $\begin{array}{l}\text { Cross- } \\
\text { sectional }\end{array}$ & $N=553$ & $\begin{array}{c}20 \text { days } \\
\text { (January-June } \\
\text { 1996) }\end{array}$ & $\begin{array}{l}\text { RFA: multivariate: } \\
\text { Controlling for demographic and socioeconomic } \\
\text { variables, means of transportation, distance to } \\
\text { ED, who referred patient to ED, regular source } \\
\text { of care, set of symptoms, regular doctor } \\
(\mathrm{OR}=2.98,95 \% \mathrm{Cl}: 1.84-4.80) \text {, and having } \\
\text { come by car }(\mathrm{OR}=2.67,95 \% \mathrm{Cl}: 1.75-4.05)\end{array}$ & 8.5 \\
\hline
\end{tabular}

(continues)

\section{Referral}

According to Coleman et al. 44, two-thirds of patients with inappropriate complaints came directly from home. Five studies showed that individuals who went to the ED on their own had 1.39 to 2.42 times greater odds of using the ED inappropriately, as compared to those referred by a health professional $13,14,35,37$ or other hospitals 16. Meanwhile, two authors 26,45 did not find this association, but Barker et al. 45 observed that patients who had been seen previously by a physician but not referred showed more inappropriate use.

\section{- Prior consultation for the current complaint}

The findings related to having a prior outpatient consultation are contradictory. An Australian study 40 found that individuals in an aged care facility who had prior contact with a physician for their current problem consulted the ED more appropriately $(\mathrm{p}=0.02)$. Meanwhile, Dale et al. 19 found that patients who had prior contact with a health professional for their current complaint had more inappropriate ED visits $(\mathrm{p}<0.001)$. Carret et al. 13 , in a multivariate analysis, showed no such association. 


\begin{tabular}{|c|c|c|c|c|c|c|c|}
\hline Article & $\begin{array}{c}\text { Year of } \\
\text { publication }\end{array}$ & Country & Design & Sample & Field period & Associated factors & Score * \\
\hline Carret et al. 13 & 2007 & Brazil & $\begin{array}{c}\text { Cross- } \\
\text { sectional }\end{array}$ & $\begin{array}{l}N=1,647 \\
(\geq 15 \text { years })\end{array}$ & $\begin{array}{c}\text { September } \\
2004\end{array}$ & 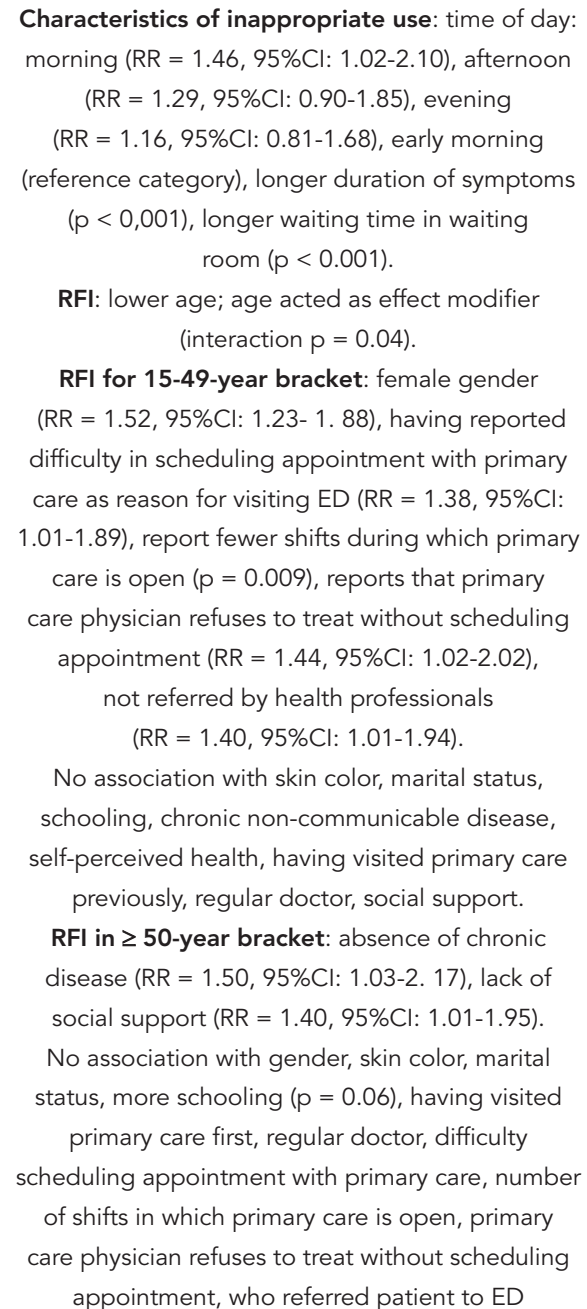 & 13 \\
\hline
\end{tabular}

* Quality score according to Downs \& Black 11.

RF: risk factor; RFA: risk factor for appropriate use; RFI: risk factor for inappropriate use; HMO: health maintenance organization.

\section{Reasons for preferring the emergency service}

\section{- Access}

The four descriptive studies that evaluated the access-related reasons for preferring the ED detected difficulties in consulting primary care, such as the primary care facility being closed, difficulty in obtaining an appointment, and waiting time as reasons for inappropriate ED use 12,13,16,21,32,35,43. Lee et al. 32 and Rajpar et al. 43 found that $35 \%$ and $50 \%$ of patients, respectively, reported closed primary care facilities as one of the reasons for inappropriate ED use, but in the latter $46.3 \%$ had not even attempted contact with primary care.

Two analytical studies found an association between difficult access to primary health care and inappropriate ED use. In the cohort study in the United States, this association had a p of 0.029 . The variables comprising this indicator, difficulty in scheduling primary care, difficult telephone contact for primary care, and longer waiting time for a primary care appointment were also associated with inappropriate ED use $(\mathrm{p}<0.03)$ when evaluated singly in the multivariate analysis 25 . Meanwhile, in the Brazilian study, difficulty in obtaining a primary care appointment, refusal by the primary care physician to 
treat patients without a previously scheduled appointment, and primary care being open for shorter hours were associated with inappropriate ED use in the 15-49-year bracket $(\mathrm{RR}=1.38,1.44$, and 1.63 , respectively) 13 .

\section{- Characteristics of ED use}

Ease in obtaining diagnostic tests and treatments at the ED were other reasons cited for preferring the ED 32,33,35,43. Rajpar et al. 43 and Lee et al. 32 reported that $3.7 \%$ and $11.4 \%$, respectively, preferred the ED due to greater ease of diagnosis. Young et al. 35 reported that $21 \%$ of patients chose the ED claiming better care or greater ease of diagnosis and treatment. Carret et al. 13, in a multivariate analysis, found no association between difficulty in obtaining tests, medicines, and referral to specialists through primary care and inappropriate ED use.

Sempere-Silva et al. 16 pointed to trust in the service provided by the ED as the principal reason for inappropriate use of this service, while in Afilalo et al. $12,7.1 \%$ of patients cited this reason. Sarver et al. 25, in a multivariate analysis, found that the greater the dissatisfaction with primary care, the greater the inappropriate use of the ED $(\mathrm{RR}=1.13$ per unit, in a score ranging from 0 to 4 ; 95\%CI: 1.01-1.25).

\section{Principal diagnosis}

The principal diagnoses found in persons that visited the ED inappropriately varied considerably from study to study, depending on the classification used in the target age bracket. Three descriptive studies indicated that the principal diagnosis or complaints among persons that consulted the ED inappropriately were respiratory problems (especially in younger patients) and digestive problems 42; abdominal pain and chest pain 12, and eye and ear complaints 16 .

In studies on association, Lui et al. 30 found that neurological and sensory organ complaints and respiratory diseases showed odds ratios of 1.85 (95\%CI: 1.76-1.95) and 1.14 (95\%CI: 1.09-1.20), respectively, of inappropriately consulting the ED among those who visited the ED with injuries and poisoning. Meanwhile Oterino etal. ${ }^{14}$ used as their comparison group those who visited the ED for infectious diseases and found more inappropriate visits among patients with skin diseases $(\mathrm{OR}=$ 4.95; 95\%CI: 2.05-11.93), musculoskeletal diseases $(\mathrm{OR}=2.60 ; 95 \% \mathrm{CI}$ : 1.25-5.38), mental health problems (OR $=2.54$; 95\%CI: 1.19-5.40), and illdefined signs and symptoms $(\mathrm{OR}=1.91$; $95 \% \mathrm{CI}$ : 1,13-3.46), while neurological and circulatory diseases showed the least inappropriate use 14 .
Dale et al. 19 , in a univariate analysis, found that musculoskeletal diseases $(p=0.028)$, infections $(p=0.002)$, skin diseases $(p<0.001)$, and genitourinary diseases $(p=0.04)$ were more frequent in inappropriate (as compared to appropriate) ED use.

\section{Discussion}

The prevalence and factors associated with inappropriate ED use varied widely, depending mainly on the criteria used and the study population. The criteria often underestimate inappropriate ED use. This occurs when using self-perceived urgency as the criterion 6,37 or when the criteria define as appropriate all cases requiring intravenous medication or any type of complementary test $13,14,16,36,41$. In this situation, the definition ends up including problems that require immediate attention, but which occur when the primary health care facility is open and operating and could thus be resolved at this level of care (as in the frequent case of patients with fever, high blood pressure, dysuria, and other complaints).

This literature review indicates that despite the above caveats, the prevalence of inappropriate ED use was consistent in a large number of studies, even across countries with different health care systems. The studies point to a high prevalence (from 20 to $40 \%$ ), concentrated more in daytime ED visits. The principal factors associated with inappropriate ED use were younger age, female gender, absence of co-morbidities, lower health spending, not being referred by a health professional, not having a regular physician or regular source of care, and difficulty in accessing primary care. No association was found between marital status, occupational status, or self-perceived health and inappropriate ED use. The associations with other variables such as race or skin color and prior consultation for the current complaint showed varied and sometimes contradictory results.

The associations between younger age and female gender and inappropriate ED use were highly consistent $13,14,21,22,25,30,34,37$. Among the elderly, the prevalence of chronic non-communicable diseases is high. In this group, ED use is considered appropriate in most cases, even in situations that could be managed at more basic levels of care, since even in such cases the patients end up having complementary tests or receiving IV medication 9,46. As for female gender, the association could be explained by the fact that women use health services more in general and maintain this same trend with inappropriate ED use 47 . 
The studies point to a direct association between socioeconomic status and inappropriate ED use $21,22,31$. This finding is plausible, since higher-income individuals have greater access to health services in general, suggesting health inequity 47 . This ends up aggravating health inequity since higher-income individuals occupy the ED with inappropriate complaints, thereby limiting access by the lower-income population that not only has greater health needs but also comes to the ED more often for truly urgent problems. Inequity also reduces the emergency department's efficiency, since patients that most need ED services are the ones with the least access. The lack of association with socioeconomic status in some studies might be related to: methodological specificities, especially in data analysis with only two categories or with a high cutoff point for the schooling variable, thus hindering the identification of associations or impeding evaluation of tendencies 34; the use of only univariate analysis 12; inclusion of all the variables at the same time in the analytical model, causing adjustment for mediating variables; or colinearity between income and schooling and underestimating the effect 48 .

The negative association between presence of co-morbidities and inappropriate ED use appears to be related to greater health needs in these cases, which require more detailed examination by the physician. Thus, most cases of co-morbidities ended up being classified as urgent ${ }^{9}$. In addition, as Petersen et al. ${ }^{34}$ showed, the association between chronic disease and inappropriate ED use appears to vary according to the type of chronic disease. Carret et al. 13 only found a negative association between presence of chronic non-communicable diseases and inappropriate ED use in the elderly. In younger patients this association was not found, perhaps due to lack of statistical power, either because chronic diseases are less prevalent in the younger age brackets or because the elderly present chronic diseases of a different type or severity. This age effect modification may explain the fact that some authors did not find an association when they studied populations that included young adults 13,37.

The majority of the authors did not find an association between self-perceived health and inappropriate ED use. The only author that found an association between poor self-perceived health and inappropriate ED use collected this variable in a household setting 25 . These findings indicate that measurement of self-perceived health in the ED is heavily affected by the moment in which this question is asked, and that it is difficult to interpret. This measurement of selfperceived health does not appear to reflect the way individuals assess their overall health status, an aspect that relates more to the way health services are used.

In relation to factors associated with access to the ED, it was clear that the cost concern influences the decision about the place of consultation. This is reinforced by studies we reviewed showing that individuals seek levels of care with the lowest cost and consult the ED less inappropriately when they have to pay $31,32,35$. Some studies that evaluated the relationship between health plan coverage (yes versus no) and inappropriate ED use did not find such an association 13,22,25,34, while according to Liu et al. 30 the association can vary according to the type of health plan. The findings suggest that individuals with high income and excellent health plans rarely consult the ED, that they have easy access to their regular physicians and services even outside of business hours, and that if necessary they can even be admitted to hospital without going through the ED. Meanwhile, individuals with health plans that impose a wide range of limitations on both coverage and speed of access appear to be similar to users of the public health system in terms of inappropriate ED use.

The same logic applies to the regular physician and regular source of care. To avoid inappropriate use, it appears not to be sufficient to have a fixed physician and regular source of care; rather, this physician or service must be easily and quickly accessible ${ }^{49}$. In addition, the regular doctor and regular source of care appear to have a greater impact on reducing inappropriate ED use in cases involving doubt about urgency. This is reinforced by the fact that studies showing an association between regular physician/ regular source of care and inappropriate ED use used a less rigorous criterion for defining such use $31,34,35$ as compared to studies that found no such association 12,13 . The importance of having access to physicians at other levels of care is also demonstrated by the consistency of the positive association between referral by a health professional and appropriate ED use 13,14,35,37.

Another aspect evaluated was prior consultation for the current complaint, which did not show consistent findings. One reason for this inconsistency was the fact that the studies evaluated different populations, such as residents of homes for the elderly, who may often even need an authorization from the institution's physician to be referred to the $\mathrm{ED} 40$. Another relevant aspect is the imprecision in defining exposure, i.e., failure to specify the time during which the prior consultation for the current complaint occurred, and the difficulty in demarcating the current complaint, thus hindering interpretation of the findings. 
Most of the studies on reasons for preferring the ED are descriptive 16,21,35,43. The small number of studies of association on reasons for preferring the ED help explain the scarcity of accumulated knowledge on the subject. The existing studies suggest that difficulty in access to primary health care is an important factor for inappropriate ED use $12,13,16,21,32,35,43$, although the difficulty is not simply the availability of primary care services (because the prevalence of inappropriate ED use increases during the day, when primary care is operating), but the possibility of obtaining care quickly 3,49 . Patients think it is so unlikely that they will get a timely primary care appointment that many do not even try 49 . They fact that they receive tests and treatment during the $\mathrm{ED}$ visit and their trust in the services provided by the ED are important enticements for choosing the ED $32,35,43$. However, typical difficulties in primary health care such as delays in performing tests and obtaining medicines and referrals to specialists were not associated with inappropriate ED use 13. Rather, this outcome was associated with dissatisfaction over primary care 25 .

Inappropriate ED use occurs in various parts of the world, thereby increasing costs and hindering access to the ED for really urgent cases 3,50. In addition, non-urgent cases are managed hastily and fail to benefit from the comprehensive care and continuity they could obtain at other levels of care 49 .

There are various studies on inappropriate ED use, but the diversity of criteria used limits the comparability of findings. Nevertheless, the socio-demographic profile of the population that consults the ED inappropriately is well defined. Meanwhile, most available studies on the reasons for consulting the ED inappropriately are descriptive, so these aspects have not been fully clarified.

This review indicates that access to primary health care plays a key role in reducing inappropriate ED use. However, intervention studies have already demonstrated that expanding the amount of services, business hours, and health professionals in primary care does not have a major impact in reducing inappropriate ED use 10,51 . This study suggests that primary care needs to provide high-quality reception of patients, with efficient triage so as to treat cases quickly when they cannot wait 4,49 . In countries with a public health care system, like Brazil, this can be facilitated by continuity in health care, since the primary care team establishes a bond and takes responsibility for the population in its coverage areas and is thus better prepared to provide adequate reception and efficient triage. In parallel, it is important to inform the population on situations in which they really should use the ED and the disadvantages of consulting the ED when the case is not truly urgent 5 . The emergency department, in turn, should develop a counter-referral system to make the tests, diagnoses, and prescriptions performed by the ED available to the other levels of care, in order to improve the care in general and avoid repeating unnecessary tests. Other measures are needed with specific populations, like those that consult the ED repeatedly ("frequent flyers"), aimed at redirecting them to other levels of care, thereby helping minimize the problem.

Future studies, especially on association, with standardized criteria to characterize inappropriate ED use, with in-depth investigation of the reasons leading the population to use emergency services inappropriately, can help establish strategies to reduce the problem. Intervention studies will also be needed to test the proposed strategies. In-depth development is also needed for criteria to define inappropriate use in order to better discriminate between cases that may need immediate attention but can be managed by primary care and those that not only require immediate attention but also require procedures not available in primary care facilities. 


\section{Resumo}

Esta revisão sistemática objetivou medir a prevalência e fatores associados ao uso inadequado do serviço de emergência, em adultos. Foram incluídos 31 artigos publicados nos últimos 12 anos. A prevalência de uso inadequado variou principalmente entre 20 e $40 \%$ e foi diretamente associada à idade e nível econômico. Mulheres, pessoas sem co-morbidades, menor gasto em saúde, sem médico regular ou local regular de cuidado e que consultavam por conta própria também consultavam mais inadequadamente com risco relativo variando entre 1,12 e 2,42. Dificuldades de acesso à atenção primária à saúde, como dificuldade de agendamento, maior time de espera para consultar e o local de atenção primária ficar menos time aberto por dia, também estiveram associados com uso inadequado. Esta revisão indica que problemas no acesso à atenção primária à saúde são determinantes de uso inadequado. Assim, a atenção primária à saúde necessita realizar um acolhimento qualificado, com uma triagem eficiente de forma a atender rapidamente os casos que não podem esperar. Além disso, é preciso esclarecer a população acerca das situações em que devem procurar o serviço de emergência e sobre as desvantagens de se consultar no serviço de emergência quando o caso não é realmente urgente.

Serviços Médicos de Emergência; Mau Uso de Serviços de Saúde; Adulto; Estudos de Avaliação

\section{References}

1. Young GP, Sklar D. Health care reform and emergency medicine. Ann Emerg Med 1995; 25:666-74.

2. Dale J, Green J, Reid F, Glucksman E, Higgs R. Primary care in the accident and emergency department: II. Comparison of general practitioners and hospital doctors. BMJ 1995; 311:427-30.

3. Gill JM. Use of hospital emergency departments for non-urgent care: a persistent problem with no easy solutions. Am J Manag Care 1999; 5:1565-8.

4. Plauth AE, Pearson SD. Discontinuity of care: urgent care utilization within a health maintenance organization. Am J Manag Care 1998; 4:1531-7.

5. Boushy D, Dubinsky I. Primary care physician and patient factors that result in patients seeking emergency care in a hospital setting: the patient's perspective. J Emerg Med 1999; 17:405-12.

6. Lowe RA, Bindman AB. Judging who needs emergency department care: a prerequisite for policymaking. Am J Emerg Med 1997; 15:133-6.

7. Richardson LD, Hwang U. Access to care: a review of the emergency medicine literature. Acad Emerg Med 2001; 8:1030-6.

\section{Contributors}

M. L. V. Carret and A. G. Fassa participated in all stages of the study, including selection of the material to be reviewed, its analysis, and writing of the article. M. D. Rodrigues participated in the evaluation of the review articles using the Downs \& Black criteria and in the final revision of the article.

\section{Acknowledgments}

This study received financial support from the Brazilian Council for Scientific and Technological Development (CNPq) in the form of Ph.D. and scientific initiation scholarships.
8. Bezzina AJ, Smith PB, Cromwell D, Eagar K. Primary care patients in the emergency department: who are they? A review of the definition of the "primary care patient" in the emergency department. Emerg Med Australas 2005; 17:472-9.

9. Aminzadeh F, DalzielWB. Older adults in the emergency department: a systematic review of patterns of use, adverse outcomes, and effectiveness of interventions. Ann Emerg Med 2002; 39:238-47.

10. Roberts E, Mays N. Can primary care and community-based models of emergency care substitute for the hospital accident and emergency (A \& E) department? Health Policy 1998; 44:191-214.

11. Downs SH, Black N. The feasibility of creating a checklist for the assessment of the methodological quality both of randomised and non-randomised studies of health care interventions. J Epidemiol Community Health 1998; 52:377-84.

12. Afilalo J, Marinovich A, Afilalo M, Colacone A, Leger R, Unger B, et al. Nonurgent emergency department patient characteristics and barriers to primary care. Acad Emerg Med 2004; 11:1302-10. 
13. Carret ML, Fassa AG, Kawachi I. Demand for emergency health service: factors associated with inappropriate use. BMC Health Serv Res 2007; 7:131.

14. Oterino D, Peiró S, Calvo R, Sutil P, Fernández O, Pérez G, et al. Utilización inadecuada de un servicio de urgencias hospitalario. Una evaluación con criterios explícitos. Gac Sanit 1999; 13:361-70.

15. Sánchez-LópezJ,Luna-del-CastilloJD,Jiménez-Moleón JJ, Delgado-Martín AE, López-de-la-Iglesia B, Bueno-Cavanillas A. Propuesta y validación del protocolo de adecuación de urgencias hospitalarias modificado. Med Clin (Barc) 2004; 122:177-9.

16. Sempere-Selva T, Peiró S, Sendra-Pina P, MartinezEspin C, Lopez-Aguilera I. Inappropriate use of an accident and emergency department: magnitude, associated factors, and reasons: an approach with explicit criteria. Ann Emerg Med 2001; 37:568-79.

17. Beland F, Lemay A, Boucher M. Patterns of visits to hospital-based emergency rooms. Soc Sci Med 1998; 47:165-79.

18. Billings J, Parikh N, Mijanovich T. Emergency department use in New York City: a substitute for primary care? Issue Brief (Commonw Fund) 2000; (433):1-5

19. Dale J, Green J, Reid F, Glucksman E. Primary care in the accident and emergency department: I. Prospective identification of patients. BMJ 1995; 311:423-6.

20. Michelen W, Martinez J, Lee A, Wheeler DP. Reducing frequent flyer emergency department visits. J Health Care Poor Underserved 2006; 17(1 Suppl): 59-69.

21. Oktay C, Cete Y, Eray O, Pekdemir M, Gunerli A. Appropriateness of emergency department visits in a Turkish university hospital. Croat Med J 2003; 44:585-91.

22. Pereira S, Oliveira-e-Silva A, Quintas M, Almeida J, Marujo C, Pizarro M, et al. Appropriateness of emergency department visits in a Portuguese university hospital. Ann Emerg Med 2001; 37:580-6.

23. Rodríguez JP, Sánchez ID, Rodríguez RP. Urgencias clínicas. Comportamiento según su gravedad. Rev Cuba Med Gen Integr 2001; 17:329-35.

24. Rubin MA, Bonnin MJ. Utilization of the emergency department by patients with minor complaints. J Emerg Med 1995; 13:839-42.

25. Sarver JH, Cydulka RK, Baker DW. Usual source of care and nonurgent emergency department use. Acad Emerg Med 2002; 9:916-23.

26. Stein AT, Harzheim E, Costa M, Busnello E, Rodrigues LC. The relevance of continuity of care: a solution for the chaos in the emergency services. Fam Pract 2002; 19:207-10.

27. Dent AW, Phillips GA, Chenhall AJ, McGregor LR. The heaviest repeat users of an inner city emergency department are not general practice patients. Emerg Med (Fremantle) 2003; 15:322-9.

28. Fajardo-Ortiz G, Ramirez-Fernandez FA. Utilización del servicio de urgencias en un hospital de especialidades. Cir \& Cir 2000; 68:164-8.

29. Gill JM, Reese CLT, Diamond JJ. Disagreement among health care professionals about the urgent care needs of emergency department patients. Ann Emerg Med 1996; 28:474-9.
30. Liu T, Sayre MR, Carleton SC. Emergency medical care: types, trends, and factors related to nonurgent visits. Acad Emerg Med 1999; 6:1147-52.

31. Shah NM, Shah MA, Behbehani J. Predictors of non-urgent utilization of hospital emergency services in Kuwait. Soc Sci Med 1996; 42:1313-23.

32. Lee A, Lau FL, Hazlett CB, Kam CW, Wong P, Wong TW, et al. Factors associated with non-urgent utilization of Accident and Emergency services: a casecontrol study in Hong Kong. Soc Sci Med 2000; 51:1075-85.

33. Coleman P, Irons R, Nicholl J. Will alternative immediate care services reduce demands for non-urgent treatment at accident and emergency? Emerg Med J 2001; 18:482-7.

34. Petersen LA, Burstin HR, O’Neil AC, Orav EJ, Brennan TA. Nonurgent emergency department visits: the effect of having a regular doctor. Med Care 1998; 36:1249-55.

35. Young GP, Wagner MB, Kellermann AL, Ellis J, Bouley D. Ambulatory visits to hospital emergency departments. Patterns and reasons for use. 24 Hours in the ED Study Group. JAMA 1996; 276:460-5.

36. Afilalo M, Guttman A, Colacone A, Dankoff J, Tselios C, Beaudet M, et al. Emergency department use and misuse. J Emerg Med 1995; 13:259-64.

37. Bianco A, Pileggi C, Angelillo IF. Non-urgent visits to a hospital emergency department in Italy. Public Health 2003; 117:250-5.

38. Gill JM, Riley AW. Nonurgent use of hospital emergency departments: urgency from the patient's perspective. J Fam Pract 1996; 42:491-6.

39. McCaig LF, Nawar EW. National Hospital Ambulatory Medical Care Survey: 2004 emergency department summary. Adv Data 2006; 23:1-29.

40. Finn JC, Flicker L, Mackenzie E, Jacobs IG, Fatovich DM, Drummond S, et al. Interface between residential aged care facilities and a teaching hospital emergency department in Western Australia. Med J Aust 2006; 184:432-5.

41. Derlet RW, Kinser D, Ray L, Hamilton B, McKenzie J. Prospective identification and triage of nonemergency patients out of an emergency department: a 5-year study. Ann Emerg Med 1995; 25:215-23.

42. Lee A, Lau FL, Hazelett CB, Kam CW, Wong P, Wong TW, et al. Morbidity patterns of non-urgent patients attending accident and emergency departments in Hong Kong: cross-sectional study. Hong Kong Med J 2001; 7:131-8.

43. Rajpar SF, Smith MA, Cooke MW. Study of choice between accident and emergency departments and general practice centres for out of hours primary care problems. J Accid Emerg Med 2000; 17:18-21.

44. Coleman EA, Eilertsen TB, Kramer AM, Magid DJ, Beck A, Conner D. Reducing emergency visits in older adults with chronic illness. A randomized, controlled trial of group visits. Eff Clin Pract 2001; 4:49-57.

45. Baker DW, Stevens CD, Brook RH. Determinants of emergency department use by ambulatory patients at an urban public hospital. Ann Emerg Med 1995; 25:311-6. 
46. Rosenblatt RA, Wright GE, Baldwin LM, Chan L, Clitherow P, Chen FM, et al. The effect of the doctor-patient relationship on emergency department use among the elderly. Am J Public Health 2000; 90:97-102.

47. Mendoza-Sassi R, Béria JU. Utilización de los servicios de salud: una revisión sistemática sobre los factores relacionados. Cad Saúde Pública 2001; 17:819-32.

48. Victora CG, Huttly SR, Fuchs SC, Olinto MT. The role of conceptual frameworks in epidemiological analysis: a hierarchical approach. Int J Epidemiol 1997; 26:224-7.
49. Campbell JL, Ramsay J, Green J, Harvey K. Fortyeight hour access to primary care: practice factors predicting patients' perceptions. Fam Pract 2005; 22:266-8.

50. Dale J, Lang H, Roberts JA, Green J, Glucksman E. Cost effectiveness of treating primary care patients in accident and emergency: a comparison between general practitioners, senior house officers, and registrars. BMJ 1996; 312:1340-4.

51. van Uden CJ, Crebolder HF. Does setting up out of hours primary care cooperatives outside a hospital reduce demand for emergency care? Emerg Med J 2004; 21:722-3.

Submitted on $03 /$ Sept/2007

Final version resubmitted on $15 / \mathrm{Feb} / 2008$

Approved on 20/Feb/2008 